\title{
Etiology and treatment of the inflammatory causes of cystoid macular edema
}

\author{
This article was published in the following Dove Press journal: \\ Journal of Inflammation Research \\ I October 2009 \\ Number of times this article has been viewed
}

\author{
Hyung Cho' \\ Assumpta Madu' \\ 'Department of Ophthalmology, \\ Albert Einstein College of Medicine, \\ Montefiore Medical Center, Bronx, \\ New York, USA
}

\begin{abstract}
Cystoid macular edema in its various forms can be considered one of the leading causes of central vision loss in the developed world. It occurs in a wide variety of pathologic conditions and represents the final common pathway of several basic processes. Therapeutic approaches to cystoid macular edema depend on a clear understanding of its contributing pathophysiologic mechanisms. This review will discuss the mechanism of ocular inflammation in cystoid macular edema with a particular focus on the inflammatory causes: post-operative, uveitic, and after laser procedures. A variety of pharmacologic agents targeting inflammatory molecules have been shown to reduce macular edema and improve visual function. However, the long-term efficacy and safety of most new therapies have yet to be established in controlled clinical trials.
\end{abstract}

Keywords: ocular inflammation, cystoid macular edema, uveitis

\section{Introduction}

Cystoid macular edema (CME) is a painless disorder, which affects the central retina or macula. Since its first recognition and description in $1974,{ }^{1} \mathrm{CME}$ has been recognized as the most common cause of decreased vision postoperatively in uneventful cataract surgery. ${ }^{2} \mathrm{CME}$ is caused by cystic accumulation of intraretinal fluid in the outer plexiform and inner nuclear layers of the retina as a result of the breakdown of the blood-retinal barrier (Figure 1). ${ }^{3} \mathrm{CME}$ can be a serious consequence of numerous ocular procedures and conditions, including cataract surgery, ocular inflammatory disease, retinal vascular diseases, and tractional disorders (Table 1). ${ }^{4}$ It is not a disease itself, rather the endpoint of a variety of processes that lead to the accumulation of fluid in the central retina. ${ }^{5}$ Clinical CME has historically been defined as a reduction in vision to $20 / 40$ or less that is attributable to ophthalmoscopically or angiographically visible CME. ${ }^{6}$ It can present with symptoms of blurred or decreased central vision, and painless retinal inflammation or swelling. In postoperative CME, vision loss is usually temporary, with infrequent incidences of permanent visual loss. ${ }^{7} \mathrm{CME}$ is often asymptomatic and may only be detected with fluorescein angiography (Figure 2) or optical coherence tomography (Figure 1). ${ }^{8}$ Studies suggest that the rate of clinical $\mathrm{CME}$ is in the range of $1 \%-2 \%,{ }^{9}$ whereas the incidence of angiographic CME may be as high as $9 \%-19 \% .^{10,11}$

Uveitic CME, on the other hand, generally has a worse prognosis and the huge negative impact of inflammatory $\mathrm{CME}$ on visual acuity has become evident in recent years. In a large cross-sectional survey of 581 patients with uveitis, $35 \%$ of all uveitis eyes had a visual acuity of 20/60 or less, of which CME had caused $42 \%$. Clinically significant
Correspondence: Hyung Cho 3450 Wayne Avenue \#9 J,

Bronx, NY 10467, USA

Tel +l 20I8199750

Email hyung.cho@gmail.com 


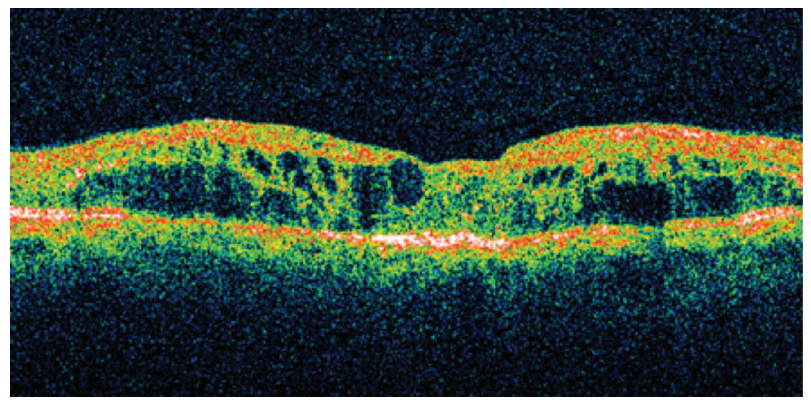

Figure I Optical coherence tomography shows intraretinal cystic spaces consistent with cystoid macular edema.

CME developed in $30 \%$ of patients with uveitis. Furthermore, the authors found that vision loss is especially severe among elderly patients and those with chronic disease. ${ }^{12}$

\section{Pathophysiologic mechanism of ocular inflammation and CME}

Arachidonic acid is metabolized by cyclooxygenase to prostaglandins which are the most important lipid derived mediators of inflammation (Figure 3). ${ }^{13}$ Surgical trauma causes a trigger of the arachidonic acid cascade, which in turn generate prostaglandins by activation of cyclooxygenase-1 (COX-1) and COX-2. Phospholipids in the cell membrane are the substrate for phospholipase A to generate arachidonic acid from which a family of chemically distinct prostaglandins and leukotrienes are produced. ${ }^{14}$ Clinical symptoms of prostaglandin production include hyperemia, miosis, impaired vision, pain and diminished visual acuity secondary to CME. ${ }^{15}$

Prostaglandin synthesis can be reduced by inhibiting phospholipase $A_{2}$, which inhibits the release of arachidonic

Table I Pathologic conditions causing macular edema

Inflammatory disorders: intraocular surgery, uveitic syndromes, laser procedures

Retinal vascular disease: diabetic retinopathy, retinal vein occlusion, hypertensive retinopathy

Choroidal vascular disease: choroidal neovascularization

Tractional maculopathies: epiretinal membrane, vitreomacular traction syndromes

Drug reactions: epinephrine, prostaglandin analogs, nicotinic acid, tamoxifen, glitazones

Inherited retinal dystrophies: retinitis pigmentosa

Retinal detachment: exudative, rhegmatogenous

Intraocular tumors: choroidal melanoma

Optic nerve head abnormalities: diabetic/hypertensive papillopathy, neuroretinitis, optic nerve pits/colobomas

Idiopathic

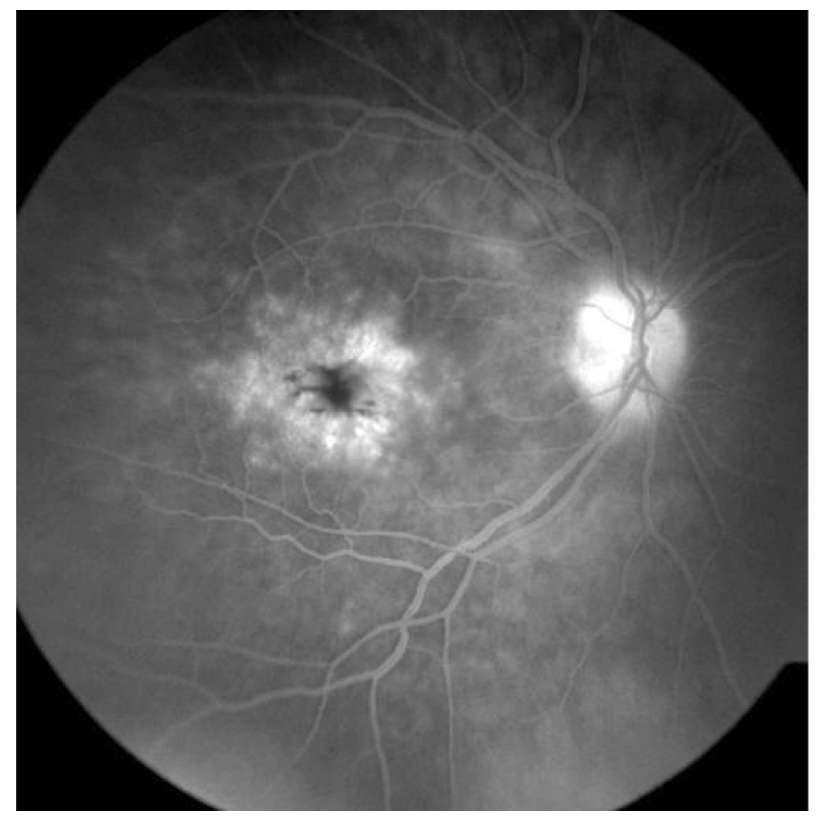

Figure 2 Fluorescein angiography, right eye. The recirculation phase of the angiogram demonstrates a classic "petalloid" appearance consistent with cystoid macular edema.

acid from cell membrane phospholipids, or by inhibiting the conversion of arachidonic acid to prostaglandins via the COX pathway. Different classes of anti-inflammatory medications may block different portions of this pathway. Corticosteroids interfere with the activity of phospholipase $A_{2}$, thereby inhibiting the release of arachidonic acid and the production of all arachidonic acid metabolites, including prostaglandins. ${ }^{16}$ In constrast, nonsteroidal anti-inflammatory drugs (NSAIDs) nonspecifically and irreversibly inhibit the synthesis of prostaglandins by interfering with the activity of COX-1 and COX-2 (Figure 3). ${ }^{16}$

Most commonly, macular edema results from pathologic hyperpermeability of retinal blood vessels, particularly the retinal capillary bed. Increased vascular permeability results in extravasation of fluid, proteins, and other macromolecules into the retinal interstitium. ${ }^{17}$ Numerous molecules may induce the retinal vascular hyperpermeability that leads to macular edema. Depending on the underlying disease entity, these may include prostaglandins and leukotrienes, protein kinase $\mathrm{C}$, nitric oxide, and various cytokines such as vascular endothelial growth factor (VEGF), tumor necrosis factor $\alpha$, insulin-like growth factor-1, and interleukins. ${ }^{18-20}$ A factor that often contributes to vascular leakage is the endothelial damage resulting from leukocyte adherence to vessel walls (leukostasis), a phenomenon mediated by nitric oxide, adhesion molecules, and other inflammatory mediators..$^{20,21}$ 


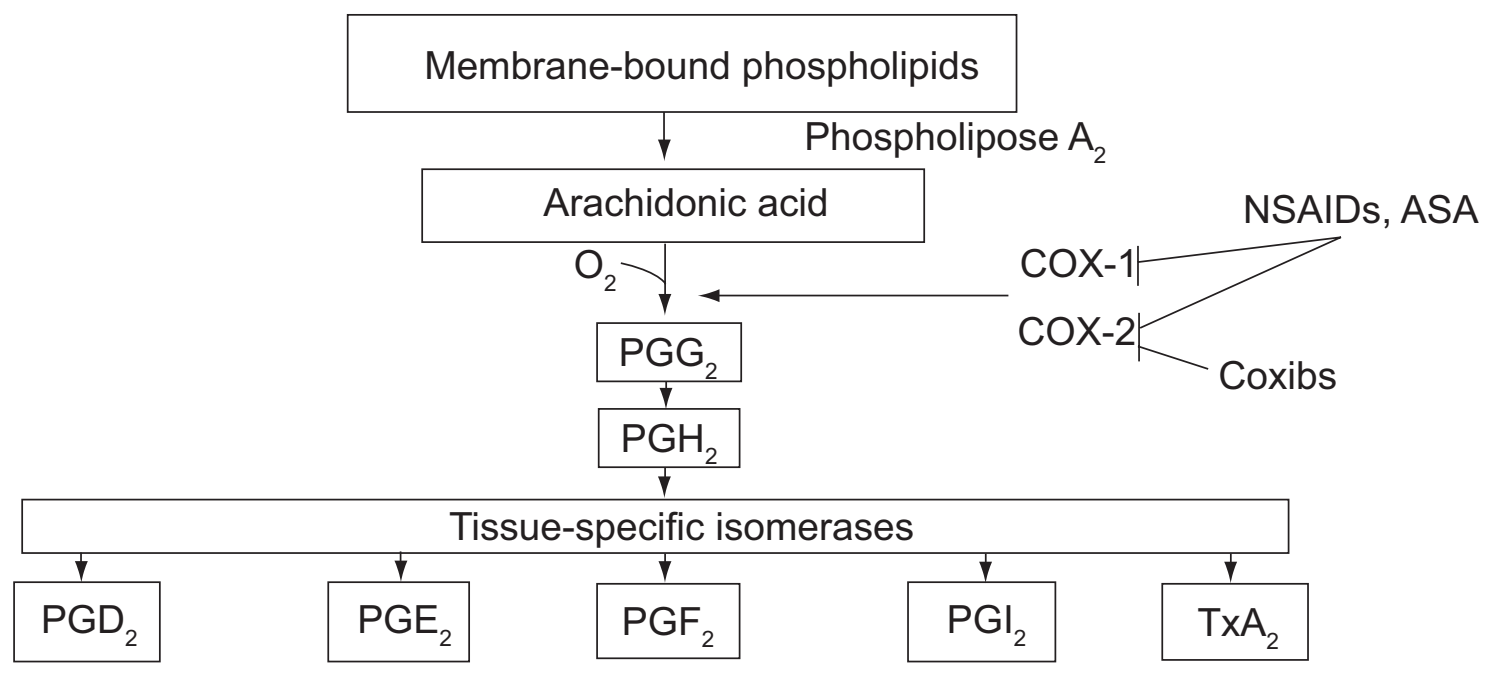

Figure 3 Prostaglandin and thromoxane biosynthesis. ${ }^{70}$ Adapted with permission from FitzGerald GA, Patrono C. The coxibs, selective inhibitors of cyclooxygenase-2. N Engl J Med. 200I;345(6):433-442.

Abbreviations: ASA, aspirin; COX, cyclooxygenase; coxibs, COX-2 inhibitors; NSAIDs, nonsteroidal anti-inflammatory drugs; PG, prostaglandin; TxA ${ }_{2}$, thromboaxane $A_{2}$.

Regardless of the various pathogenic mechanisms causing macular edema, the resulting visual acuity depends on many factors in addition to macular thickening, including duration of edema, perfusion of macular capillaries, photoreceptor impairment and/or loss, retinal pigment epithelium (RPE) dysfunction, and media opacities. ${ }^{17}$ It is perhaps not surprising that many studies have found poor correlation between macular thickness and visual acuity in eyes with macular edema of various etiologies. ${ }^{22}$

\section{Inflammatory conditions causing macular edema Intraocular surgery}

CME following cataract surgery (Irvine-Gass syndrome) remains the most common cause of visual loss following cataract surgery, and a higher incidence is seen when surgery is complicated by vitreous loss, vitreous adhesions to the cataract wound or other anterior segment structures, iris damage, or retained lens material. ${ }^{17}$ Furthermore, the risk of developing postoperative CME is substantially higher in patients with pre-exisiting conditions known to produce vasoactive stimuli, such as diabetic retinopathy and uveitis. ${ }^{17}$ Prostaglandins, as described above, have been implicated in causing macular capillary hyperpermeability in this setting.

The risk of pseudophakic CME appears to be lower with phacoemulsification surgery than with either extracapsular cataract extraction or intracapsular cataract extraction, perhaps because of reduced postoperative inflammation. ${ }^{23}$ The amount of inflammation, and hence the risk of CME, is also greater with higher phaco power $(>1 \mathrm{~J}) .{ }^{24}$ Surgical complications dramatically increase the risk of CME. A ruptured posterior capsule is associated with an $11.5 \%$ to $20 \%$ incidence of clinical CME in patients undergoing phacoemulsification. ${ }^{25,26}$ Retained lens fragments further increase the risk of clinical CME to as much as $29 \%$ after phacoemulsification. ${ }^{27}$

\section{Uveitic syndromes}

Uveitis can occur in association with autoimmune disorders, infection, and exposure to systemic medications or toxins. ${ }^{28}$ Uveitis is the fifth most common cause of visual loss in the developed world and is estimated to be responsible for up to $20 \%$ of legal blindness worldwide..$^{29} \mathrm{CME}$ is the most frequent complication of uveitis and it develops typically in patients with intermediate and posterior uveitis components, but may also be seen with isolated anterior uveitis, particularly in patients positive for human leukocyte antigen (HLA)-B27. ${ }^{17} \mathrm{CME}$ may occur in a wide variety of uveitis syndromes, whether autoimmune (eg, Pars planitis, birdshot chorioretinitis and VogtKoyanagi-Harada disease), infectious (eg, toxoplasmosis), toxic (eg, rifabutin-associated), or idiopathic (eg, sarcoidosis and idiopathic vitritis) in etiology. ${ }^{17}$

Research on CME and ocular inflammatory disease has been hampered by the lack of adequate animal models and its pathogenesis is not completely understood. ${ }^{30}$ The most important pathogenic mechanism is loss of inner bloodretinal barrier integrity caused by a variety of inflammatory mediators generated by the underlying uveitic process, including prostaglandins, leukotrienes, and various cytokines such as interleukins, tumor necrosis factor $\alpha$, and VEGF. ${ }^{19}$ 
The reliable prognostic factors distinguishing CME eyes with a potential for improvement from the eyes with definitively damaged visual acuity are not yet known. Poor contrast sensitivity, impaired color vision, chronicity of CME and advanced age of patients were all associated with impaired visual outcomes as well as macular ischemia and flat optical coherence tomography (OCT) indicating thin and atrophic macula. ${ }^{31}$

\section{Laser procedures}

The development of new or worsening macular edema is a known complication of panretinal photocoagulation (PRP) for retinal vascular disease such as diabetic retinopathy. Although the mechanism is not clearly understood, laser-induced inflammatory mediators and transudation from increased macular blood flow may both play pathogenic roles. ${ }^{17}$ Focal laser photocoagulation prior to or concurrent with PRP and dividing the PRP into multiple sessions can decrease the incidence of this complication. Approximately $1 \%$ of patients may develop CME after Nd:YAG capsulotomy. ${ }^{32}$ This complication often occurs one to five months later and is believed to be related to opening the posterior capsule rather than to the energy of the Nd:YAG laser. ${ }^{33}$

\section{Treatment options for inflammatory cystoid macular edema Initial approach}

Anti-inflammatory agents are the mainstay in the treatment of postoperative and uveitic CME. Topical therapy with corticosteroid and NSAIDs are commonly used for the treatment of macular edema. Corticosteroids (Table 2) have been shown to inhibit the inflammatory mediators and vascular permeability factors that have been associated with macular edema. ${ }^{34-36}$ Corticosteroids also can retard the loss of endothelial tight junction proteins that are important for maintaining the blood-retina barrier. ${ }^{37,38}$

A safer alternative to corticosteroids for the treatment of ocular inflammation are the NSAIDs (Table 3), which are

Table 2 Commercially available topical corticosteroids ${ }^{39-42}$

\begin{tabular}{llll}
\hline Generic & Brand & Manufacturer & Formulation \\
\hline $\begin{array}{l}\text { Difluprednate } \\
\text { Loteprednol } \\
\text { etabonate }\end{array}$ & Durezol & Sirion therapeutics & $0.05 \%$ emulsion \\
$\begin{array}{l}\text { Prednisolone } \\
\text { acetate }\end{array}$ & Pred Forte & Allergan & I\% solution \\
Rimexolone & Vexol & Alcon & I\% suspension \\
\hline
\end{tabular}

comprised of several chemically heterogeneous classes of drugs which possess potent COX inhibitory activity. Topical NSAIDs are classified into six groups based on their chemical composition: indoles, phenylacetic acids, phenylalkanoic acids, salicylates, fenamates, and pyrazolones. Salicylates, fenamates, and pyrazolones are considered too toxic to be used in the eye ${ }^{43,44}$ Most of the NSAIDs are weakly acidic drugs, which ionize at the $\mathrm{pH}$ of the lacrimal fluid and therefore have limited permeability through the anionic cornea which has an isoelectric point $\mathrm{pI}$ of 3.2. ${ }^{45}$ Reducing the $\mathrm{pH}$ of the formulation increases the unionized fraction of the drug which enhances permeation. Being acidic, NSAIDs are inherently irritant and reducing the $\mathrm{pH}$ of formulation further increase their irritation potential, as well as decrease their aqueous solubility. ${ }^{46}$ In addition, the anionic nature of NSAIDs lends to the formation of insoluble complexes with cationic quaternary ammonium preservatives, such as benzalkonium chloride..$^{47,48}$ Thus, it has proved difficult to formulate topical NSAID formulations that are comfortable when applied topically to the eye.

Studies comparing NSAIDs with corticosteroids have demonstrated no significant difference in the results between these treatments. ${ }^{44,53,54}$ However, NSAID treatment appears to be more effective than topical corticosteroids in re-establishing the blood aqueous barrier. ${ }^{53,55}$ Many studies that analyzed the effects of NSAIDs on postoperative inflammation included the concurrent administration of corticosteroids, suggesting that NSAIDs and corticosteroids have the potential for synergistic activities. ${ }^{5-57}$ The beneficial effects of NSAIDs over corticosteroids include stabilization of intraocular pressure, provision of analgesia and reduction of the risk of secondary infections. ${ }^{58}$

\section{If topical therapy fails}

\section{Steroid agents}

Resistant cases of postoperative CME and most cases of uveitic CME require higher macular concentrations of corticosteroid agents, usually achievable with posterior sub-Tenon injection. ${ }^{17}$ Cases further unresponsive to sub-Tenon corticosteroid injection may require intraocular drug concentrations attainable only with systemic or intravitreal delivery. Systemic corticosteroids are typically reserved for bilateral CME complicating noninfectious uveitis, and should be used with caution given the potential for significant systemic complications. ${ }^{17}$ In active inflammation, anti-inflammatory treatment is imperative. A recent OCT study documented a more rapid decrease of CME with oral administration than with periocular steroid injections, so an 
Table 3 Commercially available topical NSAIDs ${ }^{49-52}$

\begin{tabular}{lllll}
\hline Generic & Brand & Manufacturer & Chemical class & Formulation \\
\hline Ketorolac & Acular & Allergan & Phenylalkanoic acid & $0.5 \%$ solution \\
Diclofenac & Voltaren & Novartis & Phenylacetic acid & $0.1 \%$ solution \\
Nepafenac & Nevanac & Alcon & Arylacetic acid & $0.1 \%$ suspension \\
Bromfenac & Xibrom & Bausch and Lomb & Phenylacetic acid & $0.09 \%$ solution \\
\hline
\end{tabular}

initial treatment with oral steroids might be preferred when the rapidity of recovery is essential. ${ }^{59}$

Intravitreal triamcinolone acetonide (IVTA) used in variable dosages had a short-term effect on CME and improved vision transiently but, despite repeated injections, most patients had no sustained improvement of acuity compared with baseline. ${ }^{60}$ The side-effect profile of IVTA is significant with corticosteroid-induced intraocular pressure rises. The rate of posterior subcapsular cataract formation is higher than previously reported, and there is a small but potential risk of endophthalmitis. ${ }^{61}$

\section{Steroid-sparing drugs}

In cases of severe uveitis with CME requiring long-term treatment with moderate or high doses of corticosteroid, the use of steroid-sparing immunosuppressive drugs, in collaboration with an internist or rheumatologist, should be considered ${ }^{17}$ Harding and colleagues evaluated the use of intravitreal methotrexate (MTX) to provide an alternative for intraocular steroid therapy in patients with unilateral intermediate or posterior uveitis and/or CME who are also known steroid responders. They found that intravitreal MTX can improve visual acuity and reduce CME. ${ }^{62}$

\section{Intraocular devices}

A new treatment approach for patients requiring frequent intravitreal triamcinolone acetonide injections or chronic treatment with systemic corticosteroids and/or immunosuppressive agents is the use of an intraocular steroid sustained-delivery device. An implant containing $0.59 \mathrm{mg}$ fluocinolone acetonide demonstrated efficacy in clinical trials in patients with chronic noninfectious posterior uveitis and was recently approved by the US Food and Drug Administration (FDA) for this indication. ${ }^{63}$ The implant significantly reduced uveitis recurrences, improved visual acuity, and decreased the need for adjunctive therapy. However, the fluocinolone acetonide intravitreal implant is associated with a high rate of complications such as increased intraocular pressure, cataract, retinal detachment (RD), and endophthalmitis. ${ }^{63}$ A large, randomized, controlled clinical trial (MUST Trial) sponsored by the US National Eye
Institute is currently underway comparing the fluocinolone, implant with conventional therapy.

The dexamethasone intravitreous drug delivery system (DDS) is composed of a biodegradable copolymer of lactic acid and glycolic acid. As dexamethasone is released, the polymer slowly degrades into carbon dioxide and water. Since the implant dissolves completely, sequential implants can be placed into they eye over time without the need for surgical removal. Dexamethasone DDS was evaluated in patients with persistent macular edema resulting from uveitis or Irvine-Gass syndrome in a randomized, prospective, single-masked controlled trial. The authors found improvements in visual acuity and fluorescein leakage in this subgroup of patients. ${ }^{64}$

\section{Antivascular endothelial growth factor, interferons, and somatostatin analogues}

VEGF is a major regulator of angiogenesis and vascular permeability and is strongly implicated in the development of CME of various origins. The anti-VEGF drugs inhibit the breakdown of the blood-retinal barrier and recent data suggest that intravitreal anti-VEGF therapy with bevacizumab may be associated with anatomic and visual improvement in uveitis patients with $\mathrm{CME}$ resistant to medical therapy that persists despite control of the uveitis. ${ }^{19}$ Unfortunately, the beneficial effect was of short duration. These results suggest that, despite its limited inflammatory activity, VEGF may play a role in the pathogenesis of uveitic $\mathrm{CME}$ and that targeting this molecule may potentially be an option for treating recalcitrant $\mathrm{CME}$ in the setting of uveitis remission.

Interferons are implicated in inducing as well as in treating autoimmunity and reduced intraocular inflammation, especially in Behçet's disease. ${ }^{65}$ German studies have shown promising results of interferon- $\alpha$ (IFN $\alpha)$ in eight patients with $\mathrm{CME}$ and inactive uveitis. Side effects of the IFN $\alpha$ treatment are frequent and include flu-like symptoms, fatigue, hepatotoxicity and psychological disturbances. ${ }^{66}$ In addition, a beneficial effect of IFN $\beta$ on uveitic CME was noted in a retrospective study of 13 patients with multiple sclerosisassociated intermediate uveitis. ${ }^{67}$ 
Missotten and colleagues reported on patients with persisting macular edema in uveitis in an otherwise quiescent eye and found that the somatostatin analog octreotide longacting repeatable (LAR) had an edema-reducing effect in $70 \%$ of treated CME episodes. Successful response was related to duration of CME before start of treatment. ${ }^{68}$

\section{Surgical treatment}

Vitrectomy surgery has a role in the management of selected patients with chronic inflammatory CME. In eyes with chronic CME and vitreous adhesions to anterior segment structures following complicated cataract surgery, vitrectomy with removal of all vitreous adhesions generally results in anatomic and visual benefit. ${ }^{69}$ The current literature contains no convincing data that vitrectomy favorably modifies the course of CME in patients with chronic, recurrent uveitis.

\section{Conclusion}

Macular edema is a condition of enormous medical and socioeconomic importance because of its high prevalence and occurrence in a large number of pathologic conditions. It is the endpoint of a variety of pathophysiologic processes that can be effectively managed by recognizing and addressing the pathogenic factors that are operative in a given clinical setting. So far, there are no clear guidelines for the treatment of subclinical cystoid macular edema and every practitioner has their own strategy using a variety of pharmacologic agents, as well as vitreous surgery when needed. Although treatment options continue to expand with the development of new drugs and surgical procedures, long-term efficacy and safety of most new approaches have yet to be established in controlled clinical trials.

\section{Disclosures}

The authors have no conflict of interest to disclose.

\section{References}

1. Flach AJ. Cyclo-oxygenase inhibitors in ophthalmology. Surv Ophthalmol. 1992;36(4):259-284.

2. Flach AJ. The incidence, pathogenesis, and treatment of cystoid macular edema following cataract surgery. Trans Am Ophthalmol Soc. 1998;96:557-634.

3. Quinn CJ. Cystoid macular edema. Optom Clin. 1996;5(1): 111-130.

4. Tranos PG, Wickremasinghe SS, Stangos NT, Topouzis F, Tsinopoulos I, Pavesio CE. Macular edema. Surv Ophthalmol. 2004;49:470-490.

5. Colin J. The role of NSAIDs in the management of postoperative ophthalmic inflammation. Drugs. 2007;67(9):1291-1308.

6. Scheufele TA, Heier JS. Pseudophakic cystoid macular edema. Cataract and Refractive Surgery Today. 2005 August:54-57.

7. O'Brien TP. Emerging guidelines for the use of NSAID therapy to optimize cataract surgery and patient care. Curr Med Res Opin. 2005;21:1131-1137.
8. Roberts CW. Pretreatment with topical diclofenac sodium to decrease postoperative inflammation. Ophthalmology. 1996;103:636-639.

9. Ray S, D'Amico DJ. Pseudophakic macular edema. Semin Ophthalmol. $2002 ; 17: 167-180$

10. Ursell PG, Spalton DJ, Whitcup SM, Nussenblatt RB. Cystoid macular edema after phacoemulsification: relationship to blood-aqueous barrier damage and visual acuity. J. Cataract Refract Surg. 1999;25(11): 1492-1497.

11. Mentes J, Erakgun T, Afrashi F, Kerci G. Incidence of cystoids macular edema after uncomplicated phacoemulsification. Ophthalmologica. 2003;217(6):408-412.

12. Lardenoye CW, van Kooij B, Rothova A. Impact of macular edema on visual acuity in uveitis. Ophthalmology. 2006;113:1446-1449.

13. Ahuja M, Dhake AS, Sharma SK, Majumdar DK. Topical ocular delivery of NSAIDs. AAPS J. 2008;10(2):229-241.

14. McColgin AZ, Heier JS. Control of intraocular inflammation associated with cataract surgery. Curr Opin Ophthalmol. 2000;11:3-6.

15. Perry HD, Donnenfeld ED. An update on the use of ophthalmic ketorolac tromethamine 0.4\%. Expert Opin Pharmacother. 2006;7(1):99-107.

16. Polansky JR, Weinreb RN. Steroids as anti-inflammatory agents. In: Sears ML, editor. Pharmacology of the Eye. New York, NY: SpringerVerlag; 1984. p. 460-538.

17. Johnson MW. Etiology and treatment of macular edema. Am J Ophthalmol. 2009;147(1):11-21.

18. Saishin Y, Saishin Y, Takahashi K, Melia M, Vinores SA, Campochiaro PA. Inhibition of protein kinase $\mathrm{C}$ decreases prostaglandin-induced breakdown of the blood-retinal barrier. $J$ Cell Physiol. 2003;195:210-219.

19. Cordero Coma M, Sobrin L, Onal S, Christen W, Foster CS. Intravitreal bevacizumab for treatment of uveitic macular edema. Ophthalmology. 2007;114:1574-1579.

20. Leal EC, Manivannan A, Hosoya K, et al. Inducible nitric oxide synthase isoform is a key mediator of leukostasis and blood-retinal barrier breakdown in diabetic retinopathy. Invest Ophthalmol Vis Sci. 2007;48:5257-5265.

21. Miyamoto K, Khosrof S, Bursell SE, et al. Prevention of leukostasis and vascular leakage in streptozotocin-induced diabetic retinopathy via intercellular adhesion molecule-1 inhibition. Proc Natl Acad Sci USA. 1999;96:10836-10841

22. Catier A, Tadaoni R, Paques M, et al. Characterization of macular edema from various etiologies by optical coherence tomography. Am J Ophthalmol. 2005;140:200-206.

23. Pande MV, Spalton DJ, Kerr-Muir MG, Marshall J. Postoperative inflammatory response to phacoemulsification and extracapsular cataract surgery: aqueous flare and cells. J Cataract Refract Surg. 1996;22(Suppl 1):770-774.

24. Ferrari TM, Cavallo M, Durante G, et al. Macular edema induced by phacoemulsification. Doc Ophthalmol. 1999;97:325-327.

25. Collins JF, Krol WF, Kirk GF, Gaster RN; VA Cooperative Cataract Study Group. The effect of vitreous presentation during extracapsular cataract surgery on the postoperative visual acuity at one year. $\mathrm{Am} \mathrm{J}$ Ophthalmol. 2004;138:536-542.

26. Frost NA, Sparrow JM, Strong NP, et al. Vitreous loss in planned extracapsular cataract extraction does lead to a poorer visual outcome. Eye. 1995;9:446-451.

27. Scott IU, Flynn HW Jr, Smiddy WE, et al. Clinical features and outcomes of pars plana vitrectomy in patients with retained lens fragments. Ophthalmology. 2003;110:1567-1572.

28. Gritz DC, Wong IG. Incidence and prevalence of uveitis in Northern California: the Northern California Epidemiology of Uveitis Study. Ophthalmology. 2004;111:491-500.

29. Durrani OM, Tehrani NN, Marr JE, et al. Degree, duration, and causes of visual loss in uveitis. Br J Ophthalmol. 2004;88:1159-1162.

30. Guex-Crosier Y. The pathogenesis and clinical presentation of macular edema in inflammatory diseases. Doc Ophthalmol. 1999;97: 297-309.

31. Rothova A. Inflammatory cystoid macular edema. Curr Opin Ophthalmol. 2007;18(6):487-492. 
32. Steinert RF, Puliafito CA, Kumar SR, et al. Cystoid macular edema, retinal detachment, and glaucoma after Nd:YAG laser posterior capsulotomy. Am J Ophthalmol. 1991;112:373-380.

33. Winslow RL, Taylor BC. Retinal complications following YAG laser capsulotomy. Ophthalmology. 1985;92:785-789.

34. Leopold IH. Nonsteroidal and steroidal anti-inflammatory agents. In: Sears M, Tarkkanen A, editors. Surgical Pharmacology of the Eye. New York, NY: Raven Press; 1985. p. 83-133.

35. Nauck M, Karakiuilakis G, Perruchoud A, et al. Corticosteroids inhibit the expression of vascular endothelial growth factor gene in human vascular smooth muscle cells. Eur J Pharmacol. 1998;341:309-315.

36. Tennant JL. Cystoid maculopathy: 125 prostaglandins in ophthalmology. In: Emery JM, editor. Current Concepts in Cataract Surgery: Selected proceedings of the fifth biennial cataract surgical congress, Section 3 St. Louis, MO: CV Mosby; 1978. p. 360-362.

37. Antonetti DA, Barber AJ, Khin S, et al. Vascular permeability in experimental diabetes is associated with reduced endothelial occluding content: vascular endothelial growth factor decreases occludin in retinal endothelial cells. Diabetes. 1998;47:1953-1959.

38. Antonetti DA, Wolpert EB, DeMaio L, et al. Hydrocortisone decreases retinal endothelial cell water and solute flux conincident with increased content and decreased phosphorylation of occluding. J Neurochem. 2002;80:667-677.

39. Durezol (difluprednate) [package insert]. Tampa, FL: Sirion Therapeutics, Inc.; 2008.

40. Lotemax (loteprednol etabonate) [package insert]. Tampa, FL: Bausch and Lomb Inc.; 2006.

41. Predforte (prednisolone acetate) [package insert]. Irvine, CA: Allergan, Inc.; 2004

42. Vexol (rimexolone) [package insert]. Fort Worth, TX; Alcon, Inc.; 2003

43. Samiy N, Foster CS. The role of non-steroidal anti-inflammatory drugs in ocular inflammation. Int Ophthalmol Clin. 1996;36:195-206.

44. Flach AJ. Topical nonsteroidal anti-inflammatory drugs in ophthalmology. Int Ophtalmol Clin. 2002;42:1-11.

45. Rojanasakul Y, Robinson JR. Transport mechanisms of the cornea: characterization of barrier permselectivity. Int J Pharm. 1989;55:237-246.

46. Schalnus R. Topical nonsteroidal anti-inflammatory therapy in ophthalmology. Ophthalmologica. 2003;217:89-98.

47. Gupta M, Majumdar DK. Effect of concentration, $\mathrm{pH}$ and preservatives on in vitro transcorneal permeation of ibuprofen and flurbiprofen from non-buffered aqueous drops. Indian J Exp Biol. 1997;35:844-849.

48. Ahuja M, Dhake AS, Majumdar DK. Effect of formulation factors on in vitro permeation of diclofenac from experimental and marketed aqueous eye drops through excised goat cornea. Yakugaku Zasshi. 2006;126:1369-1375.

49. Voltaren Ophthalma (diclofenac) [package insert]. Duluth, GA: Novartis Ophthalmics; 2003.

50. Acular (ketorolac) [package insert]. Irvine, CA: Allergan Inc.; 2002.

51. Nevanac (nepafenac) [package insert]. Fort Worth, TX: Alcon Laboratories; 2005.

52. Xibrom (bromfenac) [package insert]. Irvine, CA: ISTA Pharmaceuticals, Inc.; 2006.

53. Roberts CW, Brennan KM. A comparison of topical dicolfenac with prednisolone for postcataract inflammation. Arch Ophthal. 1995;113:725-727.
54. El-Harazi SM, Ruiz RS, Feldman RM, et al. A randomized double-masked trial comparing ketorolac tromethamine $0.5 \%$, diclofenac sodium $0.1 \%$, and prednisolone acetate $1 \%$ in reducing post-phacoemulsification flare and cells. Ophthalmic Surg Lasers. 1998;29:539-544.

55. Flach AJ. Nonsteroidal anti-inflammatory drugs. In: Tasman W, editor. Duane's Foundations of Clinical Ophthalmology. Philadelphia, PA Lippincott; 1994. p. 1-32.

56. Heier JS, Topping TM, Baumann W, et al. Ketorolac versus prednisolone versus combination therapy in the treatment of acute pseudophakic cystoid macular edema. Ophthalmology. 2000;107:2034-2039.

57. Wolf EJ, Braunstein A, Shih C, Braunstein RE. Incidence of visually significant pseudophakic macular edema after uneventful phacoemulsification in patients treated with nepafenac. $J$ Cataract Refract Surg. 2007;33(9):1546-1549.

58. Hsu JK, Johnston WT, Read RW, et al. Histopathology of corneal melting associated with diclofenac use after refractive surgery. $J$ Cataract Refract Surg. 2003;29:250-256.

59. Venkatesh P, Abhas Z, Garg S, Vohra R. Prospective optical coherence tomographic evaluation of the efficacy of oral and posterior subtenon corticosteroids in patients with intermediate uveitis. Graefes Arch Clin Exp Ophthalmol. 2007;245:59-67.

60. Conti SM, Kertes PJ. The use of intravitreal corticosteroids, evidence-based and otherwise. Curr Opin Ophthalmol. 2006;17: $235-244$.

61. Jonas JB. Intravitreal triamcinolone acetonide: a change in a paradigm. Ophthalmic Res. 2006;38:218-245.

62. Hardwig PW, Pulid JS, Erie JC, et al. Intraocular methotrexate in ocular diseases other than primary central nervous system lymphoma. Am J Ophthalmol. 2006;142:883-885.

63. Jaffe GJ, Martin D, Callanan D, et al. Fluocinolone acetonide implant (Retisert) for noninfectious posterior uveitis: thirty-four-week results of a multicenter randomized clinical stud. Ophthalmology. 2006;113:1020-1027.

64. Williams GA, Haller JA, Kuppermann BD, et al. Dexamethasone posterior-segment delivery system in the treatment of macular edema resulting from uveitis or Irvine-Gass syndrome. Am J Ophthalmol. 2009;147(6):1048-1054.

65. Mackenson F, Max R, Becker MD. Interferon therapy for ocular disease Curr Opin Ophthalmol. 2006;17:567-573.

66. Deuter CM, Koetter I, Guenaydin I, et al. Interferon alpha-2a: a new treatment option for long lasting refractory cystoid macular edema in uveits? A pilot study. Retina. 2006;26:786-791.

67. Becker MD, Heiligenhaus A, Hudde T, et al. Interferon as a treatment for uveitis associated with multiple sclerosis. $\mathrm{Br} J$ Opthalmol. 2005;89:1254-1257.

68. Missotten T, van Laar JA, van der Loos TL, et al. Octreotide long-acting repeatable for the treatment of chronic macular edema in uveitis. $\mathrm{Am} \mathrm{J}$ Ophthalmol. 2007;144(6):838-843.

69. Harbour JW, Smiddy WE, Rubsamen PE, Murray TG, Davis JL, Flynn HW Jr. Pars plana vitrectomy for chronic pseudophakic cystoid macular edema. Am J Ophthalmol. 1995;120:302-307.

70. FitzGerald GA, Patrono C. The coxibs, selective inhibitors of cyclooxygenase-2. N Engl J Med. 2001;345(6):433-442.
Journal of Inflammation Research

\section{Publish your work in this journal}

The Journal of Inflammation Research is an international, peer-reviewed open-access journal that welcomes laboratory and clinical findings on the molecular basis, cell biology and pharmacology of inflammation including original research, reviews, symposium reports, hypothesis formation and commentaries on: acute/chronic inflammation; mediators of inflamma-

\section{Dovepress}

tion; cellular processes; molecular mechanisms; pharmacology and novel anti-inflammatory drugs; clinical conditions involving inflammation. The manuscript management system is completely online and includes a very quick and fair peer-review system. Visit http://www.dovepress.com/ testimonials.php to read real quotes from published authors. 